\title{
THE EFFECT OF STEAM EXPLOSION TREATMENT ON TECHNICAL HEMP FIBRES
}

\author{
Silvija Kukle ${ }^{1}$, Jānis Grāvītis ${ }^{2}$, Anna Putniṇa ${ }^{1}$, Anete Stikute ${ }^{1}$ \\ 1- Riga Technical University, Department of Design and Textile Products Technology \\ Azenes Str. 14/24, Riga, LV 1048, Latvia \\ Ph.: +(371 ) 67089816, fax: +(371) 67089160, e-mail: skukle@latnet.lv \\ 2- Latvian State Institute of Wood Chemistry, \\ Laboratory of Biomass Eco-Efficient Conversation \\ Dzerbenes Str. 27, Riga LV 1006, Latvia; e-mail: jgravit@edi.lv
}

\begin{abstract}
As hemp is a renewable resource with the high biomass yield it could be considered as potential abundant local biomass material for a wide range of applications. In this article hemp fibres architecture as a source of high strength cellulose are analysed. In experimental part steam explosion technology is applied to disintegrate technical hemp fibres to elementary fibres with the aim to find out the best way of procedure without usage to environment harmful chemical pre-treatments and looking forward to solve problems on further nano-level environment friendly hemp cellulose disintegration.
\end{abstract}

Keywords: auto-hydrolysis, cellulose, elementary fibres, hemp, steam explosion.

\section{Introduction}

Natural fibres as a renewable resource attract attention of scientists and practitioners and their applications are spreading in different industry branches. As cellulose is the most abundant biomass source from nature and has a very high theoretical strength $15 \mathrm{GPa}$ and obtainable strength $8 \mathrm{GPa}$, an increasing number of research works are devoted to inventory local cellulose sources, understanding their specifics and potential applications. [1]

Rich in cellulose are bast fibers. Flax and hemp crops have been cultivated in Latvia from prehistoric times. Growing practice shows that biomass yield of hemp is high, and hemp improves the soil structure. [2], the tall plant stems of hemp suppress weeds effectively, and diseases and pests are rarely recorded. Thereby addition of pesticides is not needed. [3] It has also been reported that hemp produces several times more of the important cellulose source, fiber component, than other crops such as corn, kenaf [4], cotton. Therefore it is of interest to determine the potential for hemp fibres to find appropriate solutions and sustainable systems. Some newer industrial uses of plant cellulose have been developed and are found to be promising, one of them are cellulose nanoparticles usage as fillers to improve mechanical and barrier properties of biocomposites [5] that is rapid developing branch of biotechnology.

The fresh hemp stem consists of a hollow cylinder of 1-5 mm thick xylem covered by 10-50 $\mu \mathrm{m}$ cambium, 100-300 $\mu \mathrm{m}$ cortexes, 20-100 $\mu \mathrm{m}$ epidermis and 2-5 $\mu \mathrm{m}$ cuticles [6].

Hemp fibers are built from different hierarchical microstructures with a microfibrils as basic units (Figure 1, above). Microfibrils are embedded in a matrix of hemicelloses and/or lignin, and they form the different cell wall layers of an elementary fiber with an average diameter ranging from 10 to $50 \mu \mathrm{m}$ [7].

Elementary fibers are bonded together with pectin and small amounts of lignin framing the next level of microstructure (Figure 1.) - technical fibers (filaments) with a diameters ranging from 50 to $100 \mu \mathrm{m}$ [8]. Filaments are fixed together with a pectin-lignin matrix to form fibers bundles in a cortex of plant stems - bast fibres. A characteristic of the hemp fibers bundle is its high lignin content from 3.7 to $8 \%$ depending on the origin and variety of plant [9].

The cortex part of the hemp stems contains bundles of 100 to 300 primary and secondary single fibres with 4 to 6 sides. The single fibers length vary from 5 to $55 \mathrm{~mm}$. Primary fibers 
nearest the stem surface are formed at the early growth stage during the phase of rapid elongation and contribute to $92-95 \%$ of the bast fibres located in cortex [11]. Cell wall thickness of primary fibers $\sim 7-13 \mu \mathrm{m}$, length $20 \mathrm{~mm}$. The secondary fibers near cambium layer are smaller (cell wall thickness 3-6 $\mu \mathrm{m}$, length $2 \mathrm{~mm}$ ) and placed only in the thick part of stem. The average area of the fiber cross-section is $\sim 780 \mu \mathrm{m} \mathrm{2}$, lumen fraction $9 \%+/-7 \%$. Therefore the load carrying of the single fibers are high (91\%) compared with wood fibers with larger lumens (small lumens has flax fibers too). [11]

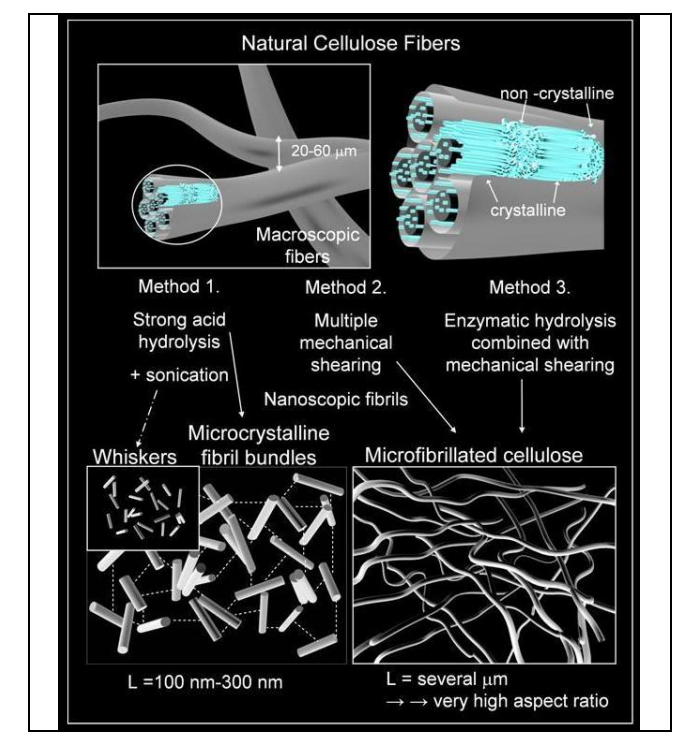

\section{Fig.1. Natural cellulose fibers structure [10]}

Microfibrils run roughly parallel to each other, following a steep helix around the cell [12]. Microfibrils are composed of crystalline and amorphous regions alternately and contain a large quantity of cellulose molecules. Individual cellulose microfibrils have diameters from 2 to $20 \mathrm{~nm}$ [13] and could be considered as a string of cellulose crystals linked along the microfibrils axis by disordered amorphous domains [14] as twists and kinks [15]. The cellulose amorphous regions are randomly oriented in spaghetti-like arrangement leading to a lower density compared to nanocrystaline regions [16].

Each type of cellulose has its own degree of polymerization and crystalline organization, which determine the fiber physical and mechanical properties. Preliminary investigations showed that degree of polymerization was 7000 in cellulose purified from raw hemp fibres [17]. The glucose monomers in cellulose form hydrogen bond both intermolecular within its own chain forming fibrils and intermolecular with neighboring chains forming microfibrils. These hydrogen bonds lead to formation of a linear crystalline structure with a high theoretical tensile strength of $15 \mathrm{GPa}$ [18].

The properties of cellulose fibers are strongly influenced by many factors such as chemical composition, cellulose type, internal fiber structure, microfibrils angle, cell dimensions and defects, which differ from different parts of a plant as well as from different plants and varieties. The low overall angle of microfibrils in hemp fibers (4 degrees) explains the high stiffness in the range 50-80 Mpa (MFA in flax fibres 10 degrees) [11]. As a result technical hemp fibers are coarser, stiffer and more susceptible to damage in mechanical processing than technical flax fibers.

Most native celluloses are mixtures of cellulose $I_{a}$ and $I_{\beta}$ [19]. Cellulose $I_{a}$ is a metastable form and can be converted into the $I_{\beta}$ by an annealing treatment [20]. In these forms polysaccharide chains is similar although the hydrogen bonding pattern is different [21]. $I_{\beta}$ 
form is present in the typical cellulose from annual plants. Some physical properties of cellulose fibers depend on the ratio between two allomorphs.

There are several different crystalline arrangements of cellulose which are denoted as cellulose I, II, III1, III $2, \mathrm{IV}_{1}$, and $\mathrm{IV}_{2}$ and they can be inter-converted depending on chemical treatment and source [22]. Cellulose has outstanding properties at the crystal level. It has been reported that the crystal modulus of cellulose I may be as high as $138 \mathrm{GPa}$, cellulose II 88 GPa, cellulose III $73 \mathrm{GPa}$, and cellulose IV $75 \mathrm{GPa}$ [23]. Hemp fibers and other plant fibers, including wood fibers mainly contain cellulose I [24].

Each natural fiber is essentially a composite in which rigid cellulose microfibrils are embedded in a soft matrix composed of lignin and hemicellulose [25]. Hemicelluloses and to some extent pectin are the primary components of the binding substance of the elementary bast fibres, while lignin plays the part of stabilizer and screen for other fibrogenious substances [26]. The degree of polymerization in hemicellulose is much lower than in cellulose ranging from 20 to 300 . By attached ferulic acid and $p$-coumaric residues, hemicellulose can form covalent bonds to lignin [27]. Hydrogen bonds are formed between xylan and cellulose. Due to this linking effect of hemicellulose, hemicellulose degradation leads to disintegration of the fibres into cellulose microfibrils resulting in lower fibre bundle strength [28]. Mainly the acid residues attached to hemicellulose make it highly hydrophilic and increase the fibres water uptake, which increases the risk of microbiological fibres degradation. It has been found that hemicellulose is thermally degraded at a lower temperature $\left(150-180^{\circ} \mathrm{C}\right)$ than cellulose $\left(200-230^{\circ} \mathrm{C}\right)$ by wet oxidation [29] and composite manufacturing [30]. The amorphous regions are susceptible to acid attack and, under controlled conditions, could be removed leaving crystalline regions intact. Since hemp belongs to the Angiosperm phylum, it contains hardwood lignin of coniferyl alcohol, sinapyl alcohol and a minor content of $p$-coumaryl alcohol [31].

To prepare harvested hemp to further processing different technologies could be used. During water retting or dew-retting the hemp bast is separated into large fibres bundles, after additional treatment is required to defibrillation the fibres bundles into single fibres and small fibres bundles. For this purpose degradation or disruption of the middle lamellae between the single fibres are necessary. Enzyme treatment [32] [33] [34], wet oxidation [35] [36] and $\mathrm{NaOH}$ treatment [37] [38] can degrade pectin and lignin in the middle lamellae between the single fibres. Physical defibrillation methods include steam explosion [39] [40] and ultrasound treatment [41].

As the content of cellulose in hemp fibres increased by steam explosion in retted hemp fibres from $73 \%$ to $85-90 \%$, but in raw hemp fibres from $60-64 \%$ to $73-75 \%$ [11] it is obvious that retting has to be included before steam explosion. The results of other investigation shows that most lignin was removed when oxidative conditions were applied since it is decomposed to low molecular phenolic compounds and oxidized to carboxylic acids [42].

\section{Materials and methods}

Disintegration of dew-retted hemp fibres of variety Bialobrzeckie grown in Agricultural Science Centre of Latgale by steam explosion was investigated.

Steam explosion auto-hydrolysis (also referred as steam explosion, steam explosion pulping, flash auto-hydrolysis or steam cracking) is principally a simple technique [42]. The biomass (wood or non-wood forest material, agricultural waste and fibre materials, waste from forestry, municipal and plantation management) for sustainable use is treated with saturated steam, usually at pressures up to 40 atmospheres. The treatment time varies from some seconds to some minutes. 
After the treatment, within a split second, the biomass is decompressed (exploded) to one atmosphere. Empirically, the so-called severity parameter or the reaction ordinate $\mathrm{R}_{\mathrm{o}}$ can be expressed as [42]:

$$
\mathrm{R}_{\mathrm{o}}=\mathrm{t} * \exp [(\mathrm{T}-100) / 14.75]
$$

where: duration of treatment ( $\mathrm{t}$, minutes) and temperature $\left(\mathrm{T},{ }^{\circ} \mathrm{C}\right)$ express the SEA severity against the base temperature $\mathrm{T}_{\text {base or reference }}=100{ }^{\circ} \mathrm{C} . \mathrm{R}_{\mathrm{o}}$ dimension is minutes but in practice using $\log \mathrm{R}_{\mathrm{o}}$. In current article $\log \mathrm{R}_{\mathrm{o}}$ fall in range from 2,36 to 3,42 (Table 1).

Similar SEA results may be achieved at different combinations of $t$ and T. However, there is certainly a contribution from other factors such as moisture content of the sample, size of particles, etc.

Among the number of chemical and physical processes occurring during the SEA treatment, two are most important:

- a functional groups are cut off during the process and thereby acid molecules are formed in the system (for example, acetic groups in hemicellululoses provide formation of the acetic acid). These newly formed acids act as catalysts of hydrolysis of the treated material (auto-hydrolysis);

- after abrupt release of the pressure at the end of the SEA process, the difference of pressure in the tissues of the material and surroundings blasts the material providing an effective defibrillation of wood or other plant biomass.

Since the lignocellulose material, under conditions of steam explosion, can provide "selfsufficient" chemical and physical transformation, both the processes, hydrolysis and defibrillation, can be achieved just by the "tools" inherent in the system itself, without any additional reagents except steam. Further fractionation of the biomass products after SEA is rather simple.

In preparation stage raw fibers were first combed to remove shives and other contaminants, after three groups of samples for experiments were prepared: for control samples group primary hemp fibres were cut into the $2 \mathrm{~mm}$ long pieces, mass of one sample $\sim 100 \mathrm{~g}$. For another groups of samples alkali pre-treatment at temperature $80{ }^{\circ} \mathrm{C}$ for one hour with two different concentrations $-3 \% \mathrm{NaOH}$ and $4 \% \mathrm{NaOH}$ were carried out with following washing and drying under normal circumstances at room temperature $\left(\sim 20^{\circ} \mathrm{C}\right)$. Experiment parameters and results are shown in Table 1.

Table 1.

\section{Experiment parameters}

\begin{tabular}{|c|c|c|c|c|c|c|c|}
\hline \multirow{2}{*}{$\begin{array}{l}\text { Sample } \\
\text { weight, } \\
\text { g }\end{array}$} & \multicolumn{2}{|c|}{ Moisture, \% } & \multirow{2}{*}{$\begin{array}{l}\text { Evaporable } \\
\text { fractions, } \\
\%\end{array}$} & \multicolumn{4}{|c|}{ STEX parameters } \\
\hline & $\begin{array}{l}\text { Before } \\
\text { STEX }\end{array}$ & $\begin{array}{l}\text { After } \\
\text { STEX }\end{array}$ & & Time, $\mathrm{s}$ & $\begin{array}{l}\text { Temperature, } \\
{ }^{0} \mathrm{C}\end{array}$ & $\begin{array}{l}\text { Pressure, } \\
\text { bar }\end{array}$ & $\log R_{0}$ \\
\hline$\sim 6,1$ & 65,1 & $\sim 75$ & 7,0 & 60 & 180 & 10 & 2,36 \\
\hline$\sim 6,1$ & 65,1 & $\sim 75$ & 7,0 & 60 & 200 & 16 & 2,94 \\
\hline$\sim 6,1$ & 65,1 & $\sim 75$ & 8,4 & 60 & 220 & 23 & 3,42 \\
\hline
\end{tabular}

After drying, they were combed and chopped to a length of about $2 \mathrm{~mm}$. The bleached fibers were subjected to disintegration by steam explosion during 60 seconds at high pressure in range from 10 to 23 bars and temperature $180-220{ }^{\circ} \mathrm{C}$. 


\section{Results and discussion}

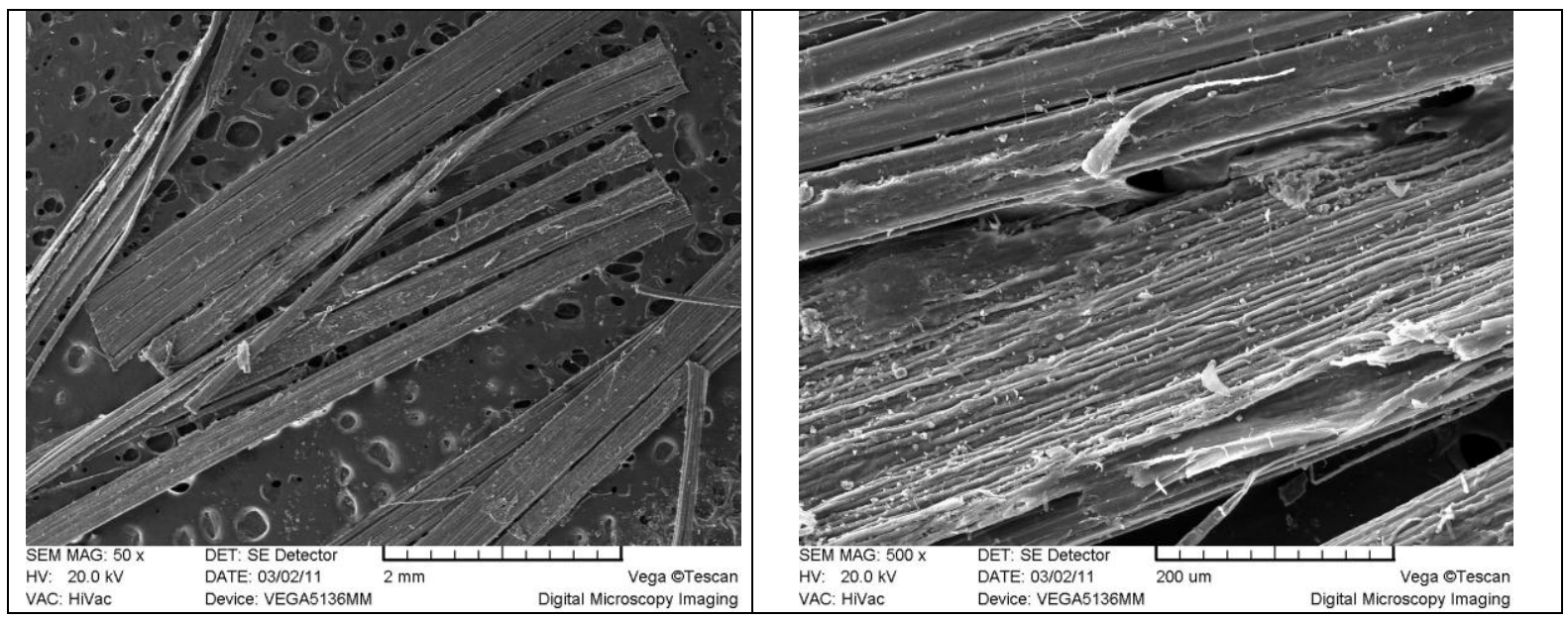

Fig 2. SEM micrographs of control group sample before steam explosion

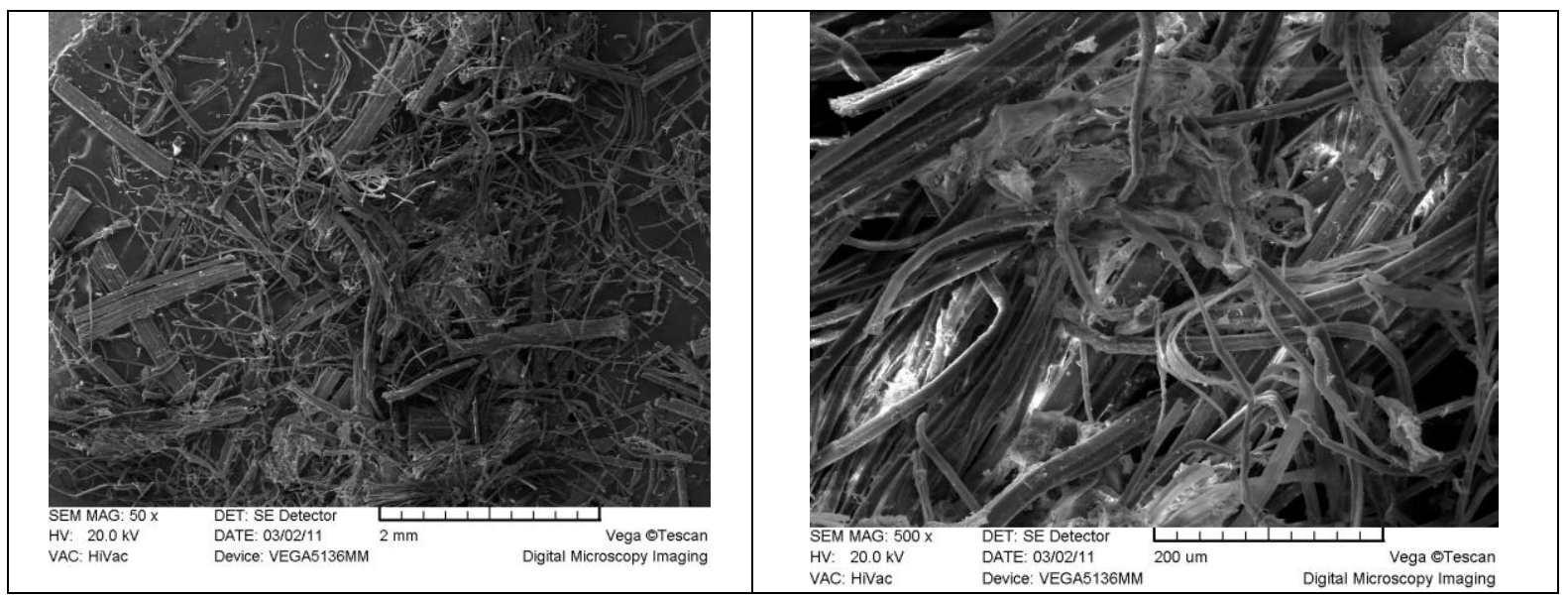

Fig 3. SEM micrographs of control group sample after steam explosion

Micrographs of control group samples subjected to steam explosion during $60 \mathrm{~s}$ at temperature $220{ }^{\circ} \mathrm{C}$ and pressure 23 bars are presented in Fig. 3.
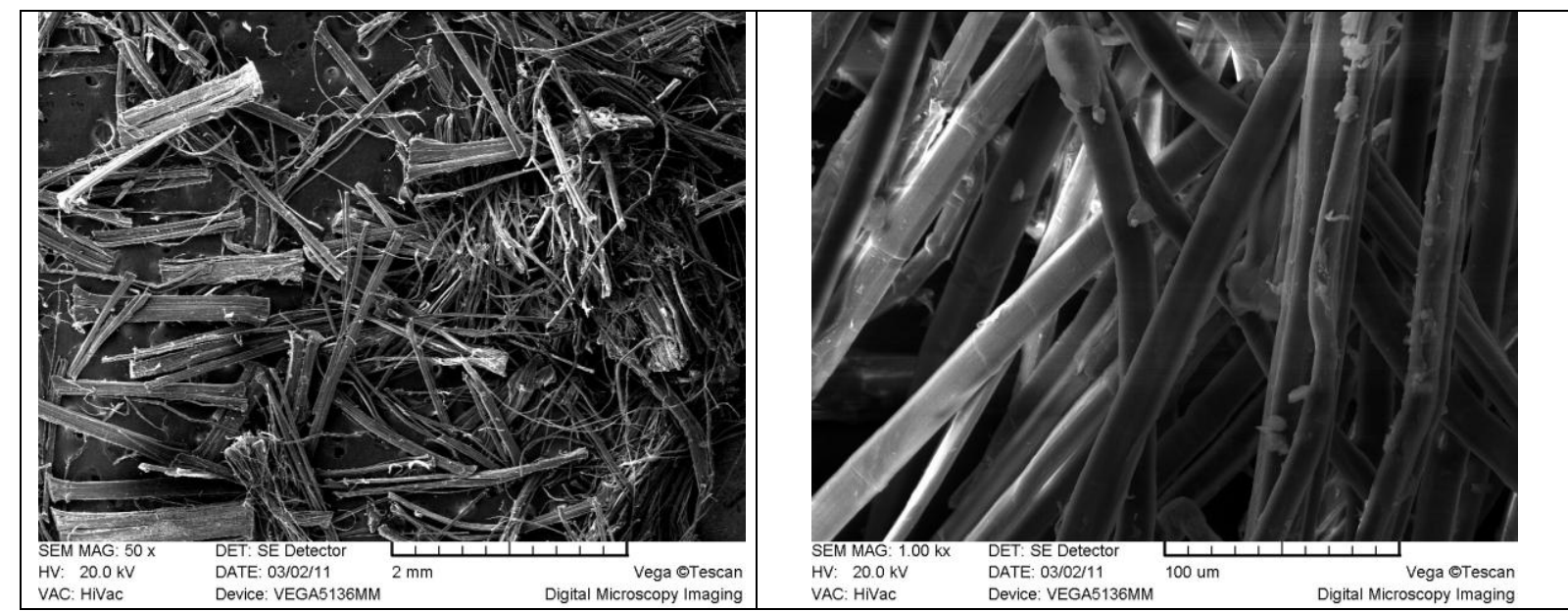

Fig 4. SEM micrographs of alkali (NaOH 4 \%) pre-treated group samples after steam explosion 
Comparison of samples micrographs before steam explosion in Figure 2 and Figure 3 shows that disruption of the middle lamellae between the single fibres are happen during steam explosion, only few pieces left undispersed (Fig. 3, left), average diameters of fibres 10-20 $\mu \mathrm{m}$.

There are two families of nano-sized cellulose particles and corresponding technologies for their preparation are reported [16]: 1) cellulose nanocrystals (whiskers), 2) microfibrillated cellulose MFC (Figure 1). The raw fibers are first milled and then submitted to alkali $\left(80{ }^{\circ} \mathrm{C}\right.$, $\mathrm{NaOH} 4 \%)$ and bleaching treatments $\left(\mathrm{NaClO}_{2} /\right.$ acetate buffer, $\left.\mathrm{pH} 4,8 ; 80{ }^{0} \mathrm{C}\right)$ to eliminate lignin and hemicelluloses with the leaving cellulose moieties intact. Bleached fibers are subjected to hydrolyzing (acid hydrolysis treatment under controlled) or disintegration (mechanical shearing at high pressure) [16]. As show our experiments, steam explosion in the range of investigated parameters allow disintegrated retted hemp technical fibres to elementary fibres or at least to loosen bonds between elementary fibres without using alkali and/or acid treatments therefore prepared hemp fibres material with 85-90\% high cellulose content for further nano-scaled disintegration by other ecological methods.

\section{Conclusions}

Hemp fibres are cellulose rich raw material with complicate inner structure, essentially a composite in which rigid cellulose microfibrils are embedded in a soft matrix composed of lignin-pectin and hemicellulose. For further processing degradation or disruption of the middle lamellae between the single fibres could be realized by physical defibrillation methods including steam explosion or chemical methods.

Steam explosion of untreated and alkali pre-treated hemp fibres show, that nor 3\%, nor $4 \%$ alkali pre-treatment does not improve level of fibres disintegration therefore retted hemp fibres could be subjected to steam explosion without chemical pre-treatment.

Further investigations are needed to exploit/develop ecofriendly nanolevel disintegration possibilities.

\section{Acknowledgements}

The study has been supported by European Social Fund financed project "Creation of a multidisciplinary scientific smart textiles development of new functional features and integration of innovative products" (RTU PVS ID 1372). The authors are grateful to the staff of Laboratory of Biomass Eco-Efficient Conversion, Latvian State Institute of Wood Chemistry.

\section{References}

1. Lilholt, H., Lawther, J.M., 2000. Natural organic fibres. Elsevier. In: Kelly, A. and Zweben, C. (Ed.), comprehensive composite materials, vol. 1, pp. 303-325.

2. Bois W.F. Hemp as a raw material for the paper industry. Bedrijfsontwikkeling, 1982,13, 851-856

3. Robinson R. The great book of hemp. 1996, Park Street Press, Main; Roe P.J., Ansell M.P. Jute-reinforced polyester composites. J Mater Sci, 1985, 20, 4015-4020.

4. Werf H.M.G., Mathijssen E.W.J.M., Haverkort A.J. The potential of hemp for sustainable fibre production: a crop physiological appraisal. Annals of Applied Biology, 1996, 129, 109-123.

5. Fan M. Elementary hemp fibres and strength. BioResources 5(4), 2010, 2307-2322.

6. Garcia-Jaldon, C., Dupeyre, D., Vignon, M.R. Fibres from semi-retted hemp bundles by steam explosion treatment. Biomass Bioenergy, 1998, 14, 251-260.

7. Candilo M., Ranalli P. and Bozzi C. Preliminary results of tests facing with the controlled retting of hemp. Industrial crops and products, 2003, 11, 197-203.

8. Bhuvan M. Mohini P. and Sain M. Mechanical properties of thermally treated hemp fibres. J. Material research innovation, 2003, 7(4), 231-238.

9. Sedelnik N. Properties of hemp fibre cottonised by biological modification of hemp hackling noils. Fibres and textiles in Eastern Europe. January/March 2004, Vol. 12, No.1 (45).

10. http://i243.photobucket.com/. 
11. Thygesen A. Properties of hemp fibre polymer composites -An optimisation of fibre properties using novel defibration methods and fibres characterisation, $\mathrm{PhD}$ thesis, The Royal Agricultural and Veterinary University of Denmark, ISBN 87-550-3440-3.

12. Bos H.L. and Donald A.M. In situ ESEM study of the deformation of elementary flax fibres. J. Material Science, 1999, 34, 3029-3034.

13. Lu J., Askeland P., Drzal L.T. Surface modification of microfibrillated cellulose for epoxy composite applications. Polymer, 2008, 49, 1285-1296.

14. Azizi Samir M.A.S., Alloin F., Dufresne A. Review of recent research into cellulosic whiskers, their properties and their applications in nanocomposite field. Biomacromolecules, 2005, 6, 612-626.

15. Montari S., Roumani M., Heux L., Vignon M. R. Topochemistry of carbaxylated cellulose nanocrystals resulting from TEMP-mediated oxidation. Maxromolecules, 2005, 38, 1665-1671.

16. Siqueira G., Bras J. And Dufresne A. Cellulosic bionanocomposites: a review of preparation, properties, applications. Polimers 2010, 2, p. 728-765. ISSN 2073-4360.

17. Thygesen, A., Madsen, F.T., Lilholt, H, Felby, C., Thomsen, A.B., 2002. Changes in chemical composition, degree of crystallisation and polymerisation of cellulose in hemp fibres caused by pre-treatment. In: Lilholt, H., Madsen, B., Toftegaard, H., Cendre, E., Megnis, M., Mikkelsen, L.P., Sørensen, B.F. (Ed.), Sustainable natural and polymeric composites - science and technology.

18. Lilholt, H., Lawther, J.M., 2000. Natural organic fibres. Elsevier. In: Kelly, A. and Zweben, C. (Ed.), Comprehensive composite materials, vol. 1, pp. 303-325.

19. Atalla R.H., VanderHart L.D. Native cellulose: A composite of two distinct crystaline forms. Science, 1984, 223, 283-285.

20. Sahena I. M., Brown R.M.J. Cellulose biosynthesis: current views and envolwing concepts. Ann. Bot., 2005, 96, 9-21.

21. Souza Lima M.M., Borsali R.M.J. Rodlike cellulose microcrystals: structure, properties and applications. Macromol. Rapid.Commun, 2004, 25, 771-787.

22. Dufresne A. Polymer nanocomposites from biological sources. In: Encyclopdia of nanosciences and nanotechnology, 3nd ed, Nalwa H.S.,ed.American Scientific Publisher, Valencia, C.A., USA.

23. Nishino T. Natural fibre resources. In: Green Composites, ed: C.Baillie, 2004, Woodhead Publishing Ltd., England.

24. Fan M.Characterization and performance of elementary hemp fibres: factors influencing tensile strength. BioResources 5(4), 2307-2322), 2010.

25. Gravitis J. Nano level structures in wood cell wall composites. Cellulose Chemistry and Technology, 2006, 40(5), 291-298.

26. Szalkowski Z.: Podstawy chemicznej technologii surowcov I wlokeien lykowych, Warszawa, 1967.

27. Bjerre AB, Schmidt AS. Development of chemical and biological processes for production of bioethanol: Optimization of the wet oxidation process and characterization of products. 1997, Riso-R-967(EN), Riso National Laboratory: pp 5-9.

28. Morvan C, Jauneau A, Flaman A, Millet J, Demarty M. Degradation of flax polysaccharides with purified endo-polygalacturonase. Carbohydrate Polymers, 1990,13, 149-163.

29. Bjerre AB, Olesen AB, Fernqvist T, Plöger A, Schmidt AS. Pretreatment of wheat straw using combined wet oxidation and alkaline hydrolysis resulting in convertible cellulose and hemicellulose. Biotechnol Bioeng, 1996, 49, 568-577.

30. Madsen, B., 2004. Properties of plant fibre yarn polymer composites - An experimental study. Ph.D. thesis, BYG-DTU, Technical University of Denmark, ISBN 87-7877-145-5.

31. Thygesen A., Geoffrey Daniel, Hans Lilholt, Thomsen A.B. Hemp fiber microstructure and use of fungal defibration to obtain fibers for composite materials. Journal of Natural fibers, 2005, 2(4), 19-37.

32. Thygesen A., Thomsen A.B., Skammelsen Schmidt A., Jorgensen H., Ahring B.K., Olsson L. Production of cellulose and hemicellulose-degrading enzymes by filamentous fungi cultivated on wet-oxidised wheat straw. Enzyme Microbial Technology, 2003, 32 (5), 606-615.

33. Madsen F.T., Burgert I., Jungnikl K., Felby C., Thomsen A.B. Effect of enzyme treatment and steam explosion on tensile properties of single hemp fiber. 12th International Symposium on Wood and Pulping Chemistry (ISWPC), 2003, Madison, P80.

34. Brühlmann F., Leupin M., Erismann K.H., Fiechter A. Enzymatic degumming of ramie bast fibers. Journal of Biotechnology, 2000,76, 43-50.

35. Thomsen A.B., Rasmussen S., Bohn V., Nielsen K.V., Thygesen A., Hemp raw materials: The effect of cultivar, growth conditions and pretreatment on the chemical composition of the fibres. Riso National Laboratory. Report No.: R-1507.

36. Mwaikambo LY, Ansell MP. The effect of chemical treatment on the properties of hemp, sisal, jute and kapok for composite reinforcement. Die Angewandte Makromolekylare Chemie, 1999, 272, 108-116. 
37. Wang H.M., Postle R., Kessler R.W., Kessler W. Removing pectin and lignin during chemical processing of hemp for textile applications. Textile Research Journal, , 2003, 73, 664-669.

38. Garcia-Jaldon C., Dupeyre D., Vignon M.R. Fibres from semi-retted hemp bundles by steam explosion treatment. Biomass \& Bioenergy, , 1998, 14, 251-260.

39. Madsen et al., 2003; Vignon M.R., Garcia-Jaldon C., Dupeyre D. Steam explosion of the woody hemp chénevotte. International Journal of Biological Macromolecules, 1995, 17, 395-404.

40. Zimmer H, Kloss D. Ultraschallaufschluss von Hanf. Ziele-Technologie-Anwendung-ResultateQualitätsmanagement. Proceedings of the Bioresource Hemp '95 Symposium; Frankfurt, Germany. NovaInstitute.

41. Klinke H.B., Ahring B.K., Schmidt A.S., Thomsen A.B. Characterization of degradation products from alkaline wet oxidation of wheat straw. Bioresour Technol, 2002, 82. 15-26.

42. Gravitis J., Dobele G., Abolins J., Tupciauskas R. \& Veveris A. Non-sulphur lignin studies under biorefinery concept and evaluation of energy consumption by steam explosion. Presentation, Paris, January, 2011. 